\title{
Criteria of Mobile Psychotherapy Games for Memory Disorder: A Systematic Literature Review
}

\author{
https://doi.org/10.3991/ijim.v14i05.13345
}

\author{
Laura Lim Sie-Yi, Noraziah ChePa $\left({ }^{\varpi}\right)$ \\ University Utara Malaysia, Kedah, Malaysia \\ aziah@uum.edu.my
}

\begin{abstract}
Games have been widely used in many domains including medical for therapy purposes. With the advancement of technology, mobile psychotherapy games have essential role in improving memory among elderly patients. There are numbers of psychotherapy games that have been developed for elderly with memory disorder. However, at one point most of the developed games are still questionable since there is lack of game development guides for this particular purpose. Designing the optimum design for the psychotherapy games, which emphasizes the users in it will be able to maximise the effectiveness of the games. Thus, this study aims to review the literatures systematically in identifying the criteria for mobile psychotherapy games specifically for memory disorder. To achieve this, three databases were used in searching literatures which are Scopus, Web of Science and ACM Digital Library. The search identified 992 articles altogether; 69 papers remains for further selection process while 909 were excluded due to irrelevancy of the focus. The selection process later refrained to 16 articles being analysed and synthesised. The selection incorporated all articles which focused directly on the psychotherapy games for memory disorder elderly patients concentrated on mobile devices. As a result, a set of important criteria for different themes on designing mobile psychotherapy game has been identified. Significant features of psychotherapy games were found in majority of the reviewed articles. These criteria will be beneficial in forming a guideline for designing and developing mobile psychotherapy games for memory disorder patients.
\end{abstract}

Keywords - Alzheimer's disease, dementia, elderly, game criteria, game intervention, memory disorder, mobile psychotherapy games.

\section{Introduction}

Research into game interventions for memory disorder related diseases has been growing exponentially since the turn of the twenty-first century. Memory disorder is pervasive in most of the elderly and also known well as cognitive decline disease [1]. According to WHO (2015), in the upcoming nearest year, the statistic of memory disorder related to diseases patients is expected to escalate. Therefore, it is important to take action to counter these memory disorder related diseases in Malaysia [2]. Most common treatments in dementia and $\mathrm{AD}$ is by using the drugs in pharmacological 
medical to control the disease other than the non-pharmacological interventions which are usually targeted for rehabilitation [3]. However, pharmacological treatments are expensive and can cause negative effects and this makes the other options a better choice and better treatment as non-pharmacological interventions are human-centred [4], [5].

Cognitive or neuro-psychological rehabilitation process is prescribed as to improve the mental or cognitive function of an injured, dysfunction or neuro-degenerated brain [6]. It is assumed that by using active simulation and engaging part of the brain are pertaining to cognitive functions can lead to recovery of its functions which is believed to effect positively on other cognitive areas of a patient [7].

The development of new technologies over pass few decades created new tools that are easy to handle such as tablet have highly diffused into society and contributed in different domains especially in neuro-psychological and cognitive rehabilitation [8]. At the foremost imperative level, humans gift method psychological feature rehabilitation need assist to repair, limit or alleviate their psychological feature deficits [9]. Cognitive therapy relates to the psychological process by which the capacity of the patient responding to system and use incoming information about allowing excessive working in life is improved or enhanced [10].

Game-based intervention is considered as a new and easy treatment for both patients and doctors or caregivers. Various games were developed for many purposes which include improvement of balancing in elderly [11], therapy tool in mental disorder [12] and use of Nintendo Wii technology in student's education [13]. Though, games that focus on elderly with dementia or $\mathrm{AD}$ are rarely being developed. Review had shown that little studies developed games that benefit as a promising technology in postponing the decline of cognitive functions in aging such as serious games and exergames [5]. However, concrete and robust evidence is required to acquire the effective designs and implementation of appropriate game-based intervention to serve its purposes in the most effective way [5].

A systematic review is an exploration of a specifically stated problem utilizing structured and straightforward criteria for defining, choosing and objectively reviewing relevant research and gathering and analyzing data from the studies included in the study [14]. The authors ' assertions of rigor in their work can be explained through a systematic review, enabling weaknesses and recommendations for future research to be established. This article is guided by the main research question in order to construct a relevant systematic review - what are the criteria of an effective games in psychotherapy for memory disorder?

With the purposes of identify the applicability and effective designs of electronic games in psychotherapy for memory disorder, we conducted a systematic review of the literature. This section discusses the intent of undertaking a systematic review when reviewing the general domain topic in the following section. The second section discusses further the portion technique and the strategy used as adapted in the Preferred Reporting Items Systematic Reviews and Meta-Analysis (PRISMA). The third section then summarizes and visualizes the past literatures extensively in order to identify, interpret and analyze relevant research on psychotherapy games for 
memory disorder. The last section concluded this the results as well as identifies future research priorities.

\section{Memory Disorder and Its Treatments}

Nowadays, the longevity of human has evolved to at least sixties or more and it is expected to reach 900 billion in coming 10 years. Statistic in shows that about $62.3 \%$ of these elderly are located in the Asian countries [15] and majority of them are expected to be in their eighties or older. In Malaysia, the fluctuation of aging population by 2020 will reach over $7.2 \%$ [16] with age more than 65 years old [17].

Cognitive impairment is one of the issues that related to the elderly with disabilities [18] where the older adults start to experience significant changes such as severe memory loss, slow response and movement and prone to more accidents [19]. Assistance in cognitive, emotional and physical for them cannot be denied which leads to development of rehabilitation with aid of flexible technology. These customized systems helps in supporting the disable older people to improve their quality of life [20]. The most common cognitive impairments diseases among elderly including dementia and $\mathrm{AD}$.

In 2010, nearly 35 million of people encounter the problem of cognitive impairment [21], whereby Asian countries contributes to large percentage of dementia patients with almost 9 million new detection annually [22]. Dementia has evolved to become the world's huge health issue in this $21^{\text {st }}$ century [19] as the number of cases doubled every 5 years and believed to be grow continuously [23]. Clearly, normal aging contributed to the development of dementia which is considered as syndrome where the elderly shows symptoms and sign of memory disorder causes by interacting aetiologies that affect brain progressively [24]. Patients will face difficulties in their daily life and routine for instant having problem to tell what is in their mind, hard to solve a simple problem and lost temper easily. The most common sign that can be seen in a patient with dementia is loss of memory other than changes in behaviour and personalities. Hence, assistance is required to take care their daily routine [20].

However, dementia is a nature that irreversible memory disorder as the cognitive function damaged permanently required the patients to be taken care and supported by other people [19]. Any symptoms in cognitive function decline of executive function, apraxia, araxia, and agnosia together with memory decline can be classified as chronic dementia [25]. These signs restricted the patients from performing a complex task in a short time for example in some games for rehabilitation, patients are unable to finish the task due to restriction of their movement which causes by the executive function decline [26].

Alzheimer's disease (AD) can be considered as one of the biggest social health and social problems, with probably the largest economic cost due to the high incidence rate in aging societies. The advancement of the disease causes problems such as memory loss, insomnia, and dementia. Some notable psychological findings are anosognosia and the lack of immediate memory [3]. The latter is the consequence of the dysfunction of episodic memory (temporal left medial area), while anosognosia is 
in relation with hypo perfusion of the right dorsolateral prefrontal cortex (DLPFC) and inferior Mini-Mental State Examination (MMSE) scoring [27].

$\mathrm{AD}$ is mainly the memory disorder disease that affect the most in sensory functions and executive motor of the patient which is different from normal neurologic pathologies that can be diagnosed from the changes in metabolic and structural of brain image. Other than that, neuro-imaging also being utilise as diagnosis tool that show different biomarkers between $\mathrm{AD}$ and healthy elderly. $\mathrm{AD}$ can evolve to different stages pathologically decreases the rate of longevity of elderly and this fact contributes to the effort to preserve the neurological functions [24].

Given the signs and symptoms of memory disorder diseases, it is urgent to find solution to prevent or delay cognitive impairment where evidence prove that elderly who are active shows slow declination of cognitive functions [28]. Therefore, several intervention and rehabilitation programs with intellectual and cognitive leisure activities are recommended to facilitate dementia patients to help in delaying the symptoms [29].

Most non-pharmacological traditional interventions are focusing on repetition of certain movements which needs high acceptance and motivation such as traditional cognitive stimulation and training programmes involve a group meeting in a designated setting in the care centre for paper-and-pencil training sessions such as Calligraphy or drawing, meditation and physical fitness activities led by a trained professional [30], [31].

Despite that, traditional interventions are costly in terms of travelling fees to the rehabilitation centres which leads to tiredness, decreasing in motivation to continue the treatment [32], [33]. Hence, digital games are introduced as a supplementary tool to the traditional rehabilitation as they are easy to use and simple in terms of interaction with the patients [34]. This technological solution of treatment are more convincing by implementing the theory of easy and simple such as a tablet device [8], [33], [35] due to the limited understanding and executive memory of the elderly patients [36]

Cognitive rehabilitation helps intervening on:

1. Disability, in search of to stimulate and enhance altered features with the aid of objection on these features

2. Promoting the employment of other mechanisms or of preserved skills (compensation)

3. Exploitation totally different methods to assist minimize issues ensuing from the pathology [37].

Other psychological feature rehabilitation therapies and protocols specialize in convalescent and maintaining psychological feature skills like memory, orientation, and communication skills as well as in motor activities facilitate people with insanity rehabilitate broken functions or maintain their current motor skills therefore on maintain the best attainable autonomy [20].

Games are rising as digital instructional and enjoyable equipment, created for a person in order to coordinate skills development [24]. This delivered to our interest to simplify, and specify assistive games development due to the reality that most of the 
Asian older people had critically restricted adventure with ICT-based systems [25]. Numerous researches have posted the outcomes of game-based cognitive activities on cognitive features which required intellectual response from participants such as problem-solving skills. Systematic literature reviews conducted by Stern and Munn [38] and Yates et al. [39] suggested that these cognitive activities such as playing board game, playing music and reading [40] have high potential in assisting memory disorder related disease patients by preventing and delaying the symptoms and development of diseases as the more they enrol in activities, the lesser the chance of having the risk of dementia [38], [39].

\section{Psychotherapy Games}

Games have been used as a popular tool in various area for example rehabilitation [41], military training [42], education [43], and many more to encourage intellectual activities of a person. The purpose of including game in rehabilitation and intervention is to boost the motivation of the patients to continuously undergo the process while the brain will keep working on all function along with the memory [44]. Other than that, game is popular of its potential usability as leisure elements to detect the individual with risk [45].

Instead of merely utilizing virtual reality, the use of games has great motivational effects on the environment when undergoing recovery tasks. Gaming at their foundation require a great deal of consideration when generating realistic play into even the most basic mechanics. Alongside suitable feedback and plenty of immediate rewards, this can create a fun experience. Exercises, due to their nature, are intrinsically repetitive and mechanical, hence why the use of a playful coat can be so useful. Nevertheless, due to the difficulty of translating rigid recovery tasks to make game mechanics fun, this persuasive coat may not be adequate as a therapeutic tool for the individual. Another pushing factors such as inspiration can be accomplished by very different means that can function together to produce common results.

In time period of accessibility, games are developed and designed with physically healthy and normal cognitive functions individual in mind. This makes the substantial majority of video games unsuitable for human beings with impairments or for the elderly. Although hints for accessibility have been created and are without difficulty reachable to all developers, it is nevertheless uncommon to locate games that carefully observe such guidelines, correctly slicing out many people from experiencing the game. Especially in the case of elderly users, the hints can be even greater strict. A game engine for rehabilitation have to supply the crucial elements to enable the many numerous necessities of sufferers to be met.

Various investigations have indicated positive effects of game on patients with memory disorder as well as other parts of cognitive functions including response time, attention, and executive functions [5], [46]. Psychotherapy through games require mental concentration, memory, and quick motor reaction in simulating brain to work and gain memory back [46]. Current non-pharmacological treatment games trains them with simple daily activities like cooking and house chores in order to train and 
simulate their memory which also known as serious games [7]. Serious games include other apps like mobile games for encouraging medical treatments and recovery, exploring the world, fostering a healthier lifestyle or opening up new creative possibilities.[47].

Game interventions were found to possess sensible benefits in boosting the treatment adherence and accessibility within health fields [48]. The flexibleness of personal deployment, the wider range of benefits, and the value of relief suggest that game-based intervention is among the most effective decision for delivering nonpharmacological treatment to individual with memory disorder related diseases [5].

The positive correlation between effectiveness and recollection in pre-treatment indicates the significance of learning and memory in the mechanism of action of this therapy and implies that neuro-feedback is suggested as it is clearly proven as an advanced stage treatment[49]. An implicit assumption that permeates the neurofeedback literature and underpins current practice is that the training process will lead to changes in the EEG, which in turn produces changes in cognitive function [50].

Although game-based treatment is a promising treatment for memory disorder disease, it is yet to be systematically incorporated in treatment plan for those suffering with the disease. The criteria of game that suits the elderly with memory disorder are yet to be gathered. Therefore, this paper intended to collect the criteria of games that suits the elderly with memory disorder with SLR methodology.

\section{$4 \quad$ Methodology}

This section discusses the approach used to retrieve article related to game-based therapy and game-based intervention model involving elderly patients with memory disorder. Preferred Reporting Materials for Systemic Investigations and MetaAnalysis (PRISMA) statement directed the review process. PRISMA is widely used in the area of computer science and information technology. The approach offers three significant advantages:

1. Specifying simple key questions that make for rigorous study

2. Establishing parameters for inclusion and exclusion

3. Attempting to review broad scientific literature datasets in a defined time frame[51].

The PRISMA Statement enables thorough search in potential digital games evaluations of terminology specific to healthcare games and their effects and coded details.

The review focused on three main journal repositories - Scopus, the Web of Science (WoS) and the Digital Library Association of Computing Machinery (ACM). Scopus is one of the largest abstracts and citation databases of peer-reviewed literature. Scopus consists of diverse subject areas such as Computer Science, Neuroscience and Psychology. WoS is the second source that the analysis utilized. It is a broad coverage of over 256 fields from Health Care Technologies and Facilities, Artificial Intelligence Computer Science, and Rehabilitation subjects. 
The researchers used the approach named PRISMA, which provides tools (Scopus and Web of Science) used to perform systemic review, requirements for inclusion and exclusion, evaluation mechanism measures (identification, screening, eligibility) and data extraction and analysis. Four stages were involved in the systematic review process. Figure 1 illustrates the four main phases involved in conducting the systematic literature review.

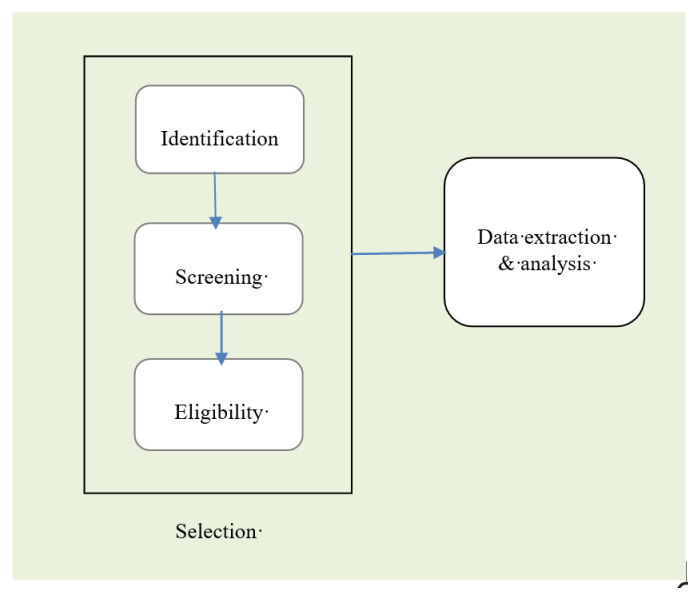

Fig. 1. Phases of systematic literature review

\subsection{Identification}

Keywords used for search process were identified in the first phase. Keywords similar and related to memory disorder, elderly people and game-based on previous studies and thesaurus are relied on. The keywords used in information searching for the three selected databases are shown in Table 1.

Table 1. Keywords and Searching Information Strategy

\begin{tabular}{|l|l|}
\hline \multicolumn{1}{|c|}{ Databases } & \multicolumn{1}{c|}{ Keywords used } \\
\hline Scopus & $\begin{array}{l}\text { TITLE-ABS-KEY (((alzheimer OR dementia) OR ("memory disorder" AND } \\
\text { ("elderly" OR "older" OR "aged" OR "senior" OR "elders")) ) AND (game OR } \\
\text { "game intervention")) }\end{array}$ \\
\hline Web of Science & $\begin{array}{l}\text { TS }=(((\text { alzheimer OR dementia) OR ("memory disorder" AND ("elderly" OR } \\
\text { "older" OR "aged" OR "senior" OR "elders"))) AND (game OR "game interven- } \\
\text { tion")) }\end{array}$ \\
\hline ACM & $\begin{array}{l}((\text { alzheimer OR dementia) OR ("memory disorder" AND ("elderly" OR "older" } \\
\text { OR "aged" OR "senior" OR "elders"))) AND (game OR "game intervention")) }\end{array}$ \\
\hline
\end{tabular}

\subsection{Screening}

Multiple conditions for inclusion and exclusion are defined. First, as far as the form of publication is concerned, only paper articles with empirical data are chosen, imply- 
ing review article, book series, essay, chapter of book and conference proceedings are omitted. Second, the non-English literatures are omitted and only concentrated on documents written in English in order to prevent ambiguity and translation difficulties. As the review process focused on the criteria of games that suits the elderly with memory disorder, articles conducted experimentally are selected. Lastly, in line with its objectives, only articles focus in games for intervention that involve elderly with related diseases are selected. At this stage, after careful screening, 14 duplicated articles were removed.

Table 2. The Inclusion and Exclusion Criteria

\begin{tabular}{|l|l|l|}
\hline \multicolumn{1}{|c|}{ Criterion } & \multicolumn{1}{|c|}{ Eligibility } & \multicolumn{1}{c|}{ Exclusion } \\
\hline Literature type & Journal (research articles) & $\begin{array}{l}\text { Journals (systematic review), book series, book, chapter in } \\
\text { book, conference proceeding }\end{array}$ \\
\hline Language & English & Non-English \\
\hline $\begin{array}{l}\text { Subject Area / } \\
\text { Categories }\end{array}$ & Computer Science & Other than Computer Science \\
\hline
\end{tabular}

\subsection{Eligibility}

The majority of the papers are reviewed and examined. Initiatives were focusing on specific experiments that addressed the questions posed. Next, the details were collected by reviewing the abstracts, then the complete articles (in-depth) to define relevant topics and sub-topics. Figure 2 shows the selection procedures.

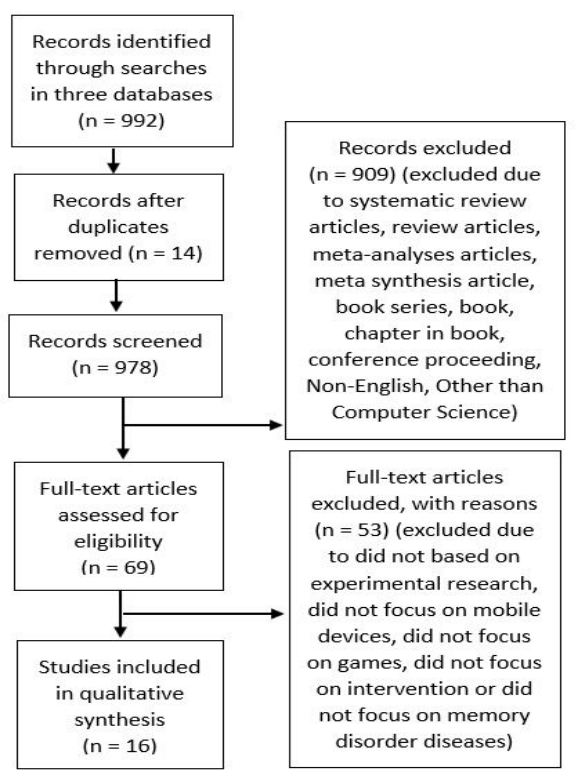

Fig. 2. Selection process of the systematic review 
In total, 951 titles and abstracts were screened to find the qualified studies for the review. Full papers of 69 studies were retrieved and evaluated according to predefine criteria including the game platform should be only mobile devices. Articles do not base on experimental research, do not focus on games, do not focus on intervention, do not focus on memory disorder diseases or do not provide any game criteria will be excluded. Based on the predefined criteria, 16 articles were included in this review. In addition, an independent reviewer independently evaluated the paper against the inclusion criteria.

\subsection{Data extraction and synthesis}

Subsequently, the key details were extracted and synthesised from the 16 studies included in our systematic review. Various types of data were extracted from the studies:

1. Demographics including the proponent and year of publication

2. Study design

3. Game title

4. Criteria of games that applied in the studies. The list of extracted criteria is covered in the following section.

\section{$5 \quad$ Finding and Results}

From the aforementioned process, the criteria for mobile psychotherapy games from 16 selected articles were identified as depicted in Table 3 . The table is sorted according to the year of study from earlier year to recent.

Table 3. List of Game Criteria

\begin{tabular}{|l|l|l|l|l|}
\hline \multicolumn{1}{|c|}{ Proponent } & $\begin{array}{l}\text { Year of } \\
\text { study }\end{array}$ & \multicolumn{1}{|c|}{ Game title } & \multicolumn{2}{|c|}{ Criteria of Game } \\
\hline $\begin{array}{l}\text { Benveniste et al. } \\
{[34]}\end{array}$ & 2010 & $\begin{array}{l}\text { MINWii Video } \\
\text { Game }\end{array}$ & $\begin{array}{l}\text { Touch-based device } \\
\text { Low cognitive and motor } \\
\text { requirement } \\
\text { Failure free gameplay } \\
\text { Simplicity in design } \\
\text { Challenge mode } \\
\text { Level of difficulties } \\
\text { Need of guidance }\end{array}$ & $\begin{array}{l}\text { Protocol and popular } \\
\text { Power reminiscence -Old } \\
\text { photo on memory } \\
\text { Putting human contact first } \\
\text { Kansei - emotion, feeling, } \\
\text { receptivity, sensible } \\
\text { Easy - familiar game }\end{array}$ \\
\hline $\begin{array}{l}\text { Bouchard et al. } \\
{[32]}\end{array}$ & 2012 & Serious Game & $\begin{array}{l}\text { Light interface } \\
\text { Warm and bright colour } \\
\text { with simple texture } \\
\text { Create good luminosity } \\
\text { Avoid dazzling the player } \\
\text { Define contrast and improve } \\
\text { depth perception with toon- } \\
\text { shading }\end{array}$ & $\begin{array}{l}\text { Advantages of multimodal } \\
\text { aspect - multisensory } \\
\text { Dimple scene } \\
\text { different types of prompt } \\
\text { Promote ecological } \\
\text { interaction }\end{array}$ \\
\hline
\end{tabular}




\begin{tabular}{|c|c|c|c|c|}
\hline $\begin{array}{l}\text { de la Gui et al. } \\
{[52]}\end{array}$ & 2013 & AlzGame & $\begin{array}{l}\text { Simple interface } \\
\text { Avoid frustration and } \\
\text { increase motivation } \\
\end{array}$ & $\begin{array}{l}\text { Expandable } \\
\text { Flexibility. } \\
\text { Touch-based device } \\
\end{array}$ \\
\hline Sisarica et al. [53] & 2013 & $\begin{array}{l}\text { Hazel Court } \\
\text { Serious Game }\end{array}$ & $\begin{array}{l}\text { Creative thinking types } \\
\text { games }\end{array}$ & \\
\hline $\begin{array}{l}\text { Xenakidis et al. } \\
{[35]}\end{array}$ & 2014 & Alzminder & $\begin{array}{l}\text { Interesting } \\
\text { Fun } \\
\text { Challenging } \\
\end{array}$ & $\begin{array}{l}\text { Interaction } \\
\text { Recall old memories }\end{array}$ \\
\hline Tong et al. [54] & 2014 & $\begin{array}{l}\text { whack-a-mole } \\
\text { game }\end{array}$ & $\begin{array}{l}\text { Touch-based device } \\
\text { Setting }\end{array}$ & \\
\hline $\begin{array}{l}\text { Kitakoshi et al. } \\
{[55]}\end{array}$ & 2015 & $\begin{array}{l}\text { Memory game- } \\
\text { memorizing and } \\
\text { remembering } \\
\text { images }\end{array}$ & $\begin{array}{l}\text { Enjoyment } \\
\text { Motivation } \\
\text { Level of difficulty }\end{array}$ & $\begin{array}{l}\text { Frequency - take a break } \\
\text { Response }\end{array}$ \\
\hline Cardullo et al. [8] & 2016 & $\begin{array}{l}\text { Padua } \\
\text { Rehabilitation } \\
\text { Tool (PRT) }\end{array}$ & $\begin{array}{l}\text { Simple interface } \\
\text { Tap gesture } \\
\text { Feedback } \\
\text { Errorless learning approach }\end{array}$ & $\begin{array}{l}\text { Motivation } \\
\text { Avoid frustration } \\
\text { Language } \\
\text { Interesting - curiosity }\end{array}$ \\
\hline $\begin{array}{l}\text { Westphal et al. } \\
{[56]}\end{array}$ & 2017 & $\begin{array}{l}\text { Piece by Piece } \\
\text { game }\end{array}$ & \begin{tabular}{|l} 
Avoid frustration \\
Something familiar \\
Tutorial needed
\end{tabular} & $\begin{array}{l}\text { Different challenge level } \\
\text { Language }\end{array}$ \\
\hline Orji et al. [57] & 2017 & $\begin{array}{l}\text { Space-invaders } \\
\text { themed game }\end{array}$ & $\begin{array}{l}\text { Competition - Comparison } \\
\text { Simulation } \\
\text { Self-monitoring } \\
\text { Suggestion }\end{array}$ & $\begin{array}{l}\text { Customization - } \\
\text { Personalization } \\
\text { Prize/praise } \\
\text { Reward } \\
\text { Cooperation } \\
\end{array}$ \\
\hline Vallejo et al. [58] & 2017 & $\begin{array}{l}\text { Cooking Serious } \\
\text { Game }\end{array}$ & $\begin{array}{l}\text { Easy to use } \\
\text { Fun to do }\end{array}$ & Ecological \\
\hline Vallejo et al. [59] & 2017 & $\begin{array}{l}\text { Task-based } \\
\text { Serious Game }\end{array}$ & $\begin{array}{l}\text { Functional } \\
\text { Enjoyable } \\
\text { Motivation }\end{array}$ & $\begin{array}{l}\text { User-friendly } \\
\text { Previous experience - } \\
\text { familiar game }\end{array}$ \\
\hline $\begin{array}{l}\text { Lithoxoidou et al. } \\
{[37]}\end{array}$ & 2018 & Puzzle Game & $\begin{array}{l}\text { Different motives } \\
\text { Entertainment elements } \\
\text { Matching to lifestyle } \\
\text { Lesser commitment of } \\
\text { player } \\
\text { Level of difficulties } \\
\text { Quest }\end{array}$ & $\begin{array}{l}\text { Free to leave or come back } \\
\text { without penalties } \\
\text { Incentives } \\
\text { Small groups } \\
\text { Language }\end{array}$ \\
\hline Panagl et al. [60] & 2018 & Amicasa & $\begin{array}{l}\text { Interactive association } \\
\text { Search games }\end{array}$ & $\begin{array}{l}\text { Physical activities } \\
\text { Playful cognitive test }\end{array}$ \\
\hline Iizuka et al. [29] & 2018 & GO-game & $\begin{array}{l}\text { Not complex and not } \\
\text { difficult to learn the game }\end{array}$ & $\begin{array}{l}\text { Simple rule but high } \\
\text { intellectual stimulation }\end{array}$ \\
\hline \begin{tabular}{|l} 
Altmeyer et al. \\
{$[61]$}
\end{tabular} & 2018 & Skip-Bo & \begin{tabular}{|l} 
Motivation \\
Collaboration
\end{tabular} & $\begin{array}{l}\text { Encouraged to explore } \\
\text { technology }\end{array}$ \\
\hline
\end{tabular}

In the studies done by Benveniste et al. [34], de la Gui et al. [52], Tong et al. [54] and Cardullo et al. [8] suggested it is better to use touch based device which is lightweight, portable, and easy to sanitize after each use. All the games utilize the same method of response ("tap gesture").

Simple interface and simple design of games are supported by [34], [32], [52] and [8]to allow an easy interaction to all the users. As elderly people lose their abilities, it is necessary to motivate them through amusing but simple user interfaces. Other than 
simple interface, the game have to be easy to play and simple enough for the elderly to adapt [34] [58] [29]. Complex and difficult games is very hard for those with low cognitive function to learn. It is more suggested that the game is something familiar or based on the previous experience for memory recall[34] [35] [56] [37]. Nevertheless, this review focuses on memory disorder thus majority of the games possessed the criteria of reminiscence or matching to lifestyle. Proven effectiveness of reminiscence therapy in improving cognitive function and psychological well-being set our priorities in designing the game's aesthetics to promote warmth and familiarity that was distinctly generational and cultural [56].

Simple rule but high intellectual stimulation games with creative thinking are suggested by [37] [53] [59] [60] [61] to allow the user to explore their critical mind as well as improve their functional thought. However, [34] do not agree with high intellectual game but in fact the author suggested low cognitive and motor requirement games since the targeted users are memory disorder patients with cognitive impairment.

Although, games should be fun and enjoyable. Older gamers play games to relax and have fun and value choice, enjoyment and meaningful play. This criteria can be seen in [8] [35] [37] [55] [58] [59] [61] as those are fun games to avoid bored after a particular time as well as increase their engagement towards the game. Fun alone is not enough to help the patients with memory disorder, it need to corporate with different challenge level or different quests as suggested by [34] [35] [37] [55] [56][ 57]. In the context of task performance, when one's skill is too low and a task too hard, people become anxious. Alternatively, if the task is too easy and the skill is too high, people become bored. For the option of game play in rehabilitation games for patients with memory disorder, difficulty or challenge options should be increased gradually and not at a high rate. This is to avoid deterring the users from using the game, which will eventually help them to enhance their skills and condition.

However, it is important to avoid frustration[8] [52] [56] when user fail the challenges. Appropriate applications should show positive and encouraging messages when the user fails. In this way, the user is motivated to continue playing and improving their cognitive abilities. Another option to avoid frustration is by providing help and hints during the challenges [8] [32] [55] [57]. Help should be prompted consistently when user experience difficulties or when user take too much time to move the next step in order to keep them in the game.

Motivation that keep user stay in the games play an essential role [8] [52] [55][ 59] [61]. Starting with a very easy task, the user can experience success increasing the motivation and decreasing the sense of frustration derived from doing a task harder than what they are able to do. Besides, by provide rewards when user completed one level is suggested to increase the motivation of the user [37] [57]. Another important aspect that could decrease the motivation of user is the usage of language that user do not understand. In the studies done by [8] [37] [56], languages used in the games affect the user as if it communicate with each other. More understanding can be achieved with the language that user familiar indirectly motivate the user to continue engage with the game as they do not feel demotivated by the familiarity. 
Games specifically designed for the elderly should be able to provide tutorial to help make things more user-friendly[34] [56] [59]. Tutorials available before starting the games and it also can be available during the game to allow user to recall what are the rules for the games. On the other hand, they should allow user to take a break or to pause the game when they feel tired without any penalties [37] [55]. This can help in lessen the commitment of the player. It is proposed in [34] [35] [37] [57][ 61] to create a small group within the player to allow them to have social interaction. Users can cooperate to finish a challenge or a difficult task together.

Other than game features aforementioned, the interface design of the game also should suit the targeted user which are the elders. Older people tend to distinguish the limits and boundaries of points on a floor, and their sense of depth is diminished. In comparison, $\mathrm{AD}$ patients often will lose the ability to accurately distinguish an image and the backdrop on which it is depicted and will find it more difficult to detect detail while gazing at darkened items or places. Thus, as proposed by [32] [54], the setting should be friendly towards elders. When choosing various colors for the setting and objects, along with various colors for images, contrast color makes it easier for players to identify them. Contrasts and perception of shape can be improved by using a shader to exaggerate the outline thickness of the object, as in a well-known technique called toon-shading in video games. Produce a good luminosity to stop distracting the player to concentrate on a significant target or place in the game as long because it will not interrupt his sight. Bright warm colors like red, orange and yellow are better seen by elderly people than others.

\section{Conclusion}

This systematic review has identified the criteria possessed in the mobile psychotherapy games that developed for memory disorder patients. Based on the systematic reviews performed, the authors have identified the criteria that have been proposed by different articles. These criteria will be further extended to different themes in future.

As a result, a set of important criteria for different themes on designing mobile psychotherapy game has been identified. Significant features of psychotherapy games were found in majority of the reviewed articles. These criteria will be beneficial in forming a guideline for designing and developing mobile psychotherapy games for memory disorder patients.

\section{$7 \quad$ Acknowledgement}

This research is funded by a grant from Ministry of Higher Education of Malaysia (FRGS Grant 14390). Authors fully acknowledged MOHE for the approved fund which makes this important research viable and effective. 


\section{References}

[1] Lee, H. Chang, C. Huang, W. Cheng, P. Lee, and H. Chao, "Memory training program for older adults," Educ. Gerontol., vol. 44, no. 10, pp. 614-626, 2018.https://doi.org/10. 1080/03601277.2018.1511099

[2] Chan, P. S. Yap, and F. Z. Khalaf, "Factors associated with high strain in caregivers of Alzheimer's disease (AD) in Malaysia," Geriatr. Nurs. (Minneap)., vol. 000, pp. 1-6, 2019.

[3] J. Vigil and L. Tataryn, "Neurotherapies and Alzheimer's: A Protocol-oriented Review," NeuroRegulation, vol. 4, no. 2, pp. 79-94, 2017. https://doi.org/10.15540/nr.4.2.79

[4] H. Kavirajan and L. S. Schneider, "Efficacy and adverse effects of cholinesterase inhibitors and memantine in vascular dementia: a meta-analysis of randomised controlled trials," Lancet Neurol., vol. 6, no. 9, pp. 782-792, 2007. https://doi.org/10.1016/S14744422(07)70195-3

[5] J. Zheng, X. Chen, and P. Yu, "Game-based interventions and their impact on dementia: a narrative review," Australas. Psychiatry, vol. 25, no. 6, pp. 562-565, 2017. https://doi.org/10.1177/1039856217726686

[6] M. Pąchalska, Rehabilitacja neuropsychologiczna: Procesy poznawcze $i$ emocjonalne. Wydawnictwo Uniwersytetu Marii Curie-Skłodowskiej, 2008.

[7] I. Laskowska et al., "A serious game - a new training addressing particularly prospective memory in the elderly," Bio-Algorithms and Med-Systems, vol. 9, no. 3, pp. 155-165, 2013. https://doi.org/10.1515/bams-2013-0016

[8] S. Cardullo, P. M. Valeria, T. Ilaria, P. Ambra, L. Gamberini, and D. Mapelli, "Padua Rehabilitation Tool: A Pilot Study on Patients with Dementia," 2016. https://doi.org/10. 1007/978-3-319-40216-1 31

[9] B. A. Wilson, "Towards a comprehensive model of cognitive rehabilitation," Neuropsychol. Rehabil., vol. 12, no. 2, pp. 97-110, 2002. https://doi.org/10.1080/ 09602010244000020

[10] M. M. Sohlberg and C. A. Mateer, Introduction to cognitive rehabilitation: Theory and practice. Guilford Press, 1989.

[11] M. Agmon, C. K. Perry, E. Phelan, G. Demiris, and H. Q. Nguyen, "A pilot study of Wii Fit exergames to improve balance in older adults," J. Geriatr. Phys. Ther., vol. 34, no. 4, pp. 161-167, 2011. https://doi.org/10.1519/JPT.0b013e3182191d98

[12] M. H. Moussa et al., "Video games as a complementary therapy tool in mental disorders: PlayMancer, a European multicentre study," J. Ment. Heal., vol. 21, no. 4, pp. 364-374, 2012. https://doi.org/10.3109/09638237.2012.664302

[13] N. Vernadakis, A. Gioftsidou, P. Antoniou, D. Ioannidis, and M. Giannousi, "The impact of Nintendo Wii to physical education students' balance compared to the traditional approaches," Comput. Educ., vol. 59, no. 2, pp. 196-205, 2012. https://doi.org/10. 1016/j.compedu.2012.01.003

[14] J. P. T. Higgins et al., "The Cochrane Collaboration's tool for assessing risk of bias in randomised trials," Bmj, vol. 343, p. d5928, 2011. https://doi.org/10.1136/bmj.d5928

[15] W. He, D. Goodkind, and P. Kowal, "An aging world: 2015 International Population Reports," Int. Popul. Reports, 2016.

[16] World Health Organization, "Ageing and health," Cambridge Handbook of Psychology, Health and Medicine, Second Edition, 2014. [Online]. Available: https://www.who.int/news-room/fact-sheets/detail/ageing-and-health. [Accessed: 24-Apr2019].

[17] Compendium of Environment Statistics (CES), "Population Projection (Revised), Malaysia, 2010-2040,” Dep. Stat. Malaysia, no. June, pp. 5-9, 2016.

[18] H. Agüero-Torres, V. S. Thomas, B. Winblad, and L. Fratiglioni, "The impact of somatic and cognitive disorders on the functional status of the elderly," J. Clin. Epidemiol., vol. 55, no. 10, pp. 1007-1012, 2002. https://doi.org/10.1016/S0895-4356(02)00461-4 
[19] S.-J. Park, H.-D. Chang, and K. Kim, "Effectiveness of the Serious Game 'Rejuvenesce Village" in Cognitive Rehabilitation for the Elderly," Int. J. E-Health Med. Commun., vol. 6, no. 1, pp. 48-57, 2015. https://doi.org/10.4018/IJEHMC.2015010104

[20] A. Tapus, "Improving the quality of life of people with dementia through the use of socially assistive robots," Proc. - 2009 Adv. Technol. Enhanc. Qual. Life, AT-EQUAL 2009, pp. 81-86, 2009. https://doi.org/10.1109/AT-EQUAL.2009.26

[21] T. Zhang, C.-C. Lin, T.-C. Yu, J. Sun, W.-C. Hsu, and A. M.-K. Wong, "Fun cube based brain gym cognitive function assessment system," Comput. Biol. Med., vol. 84, pp. 1-8, 2017. https://doi.org/10.1016/j.compbiomed.2017.03.003

[22] M. Satoh et al., "Physical Exercise with Music Maintains Activities of Daily Living in Patients with Dementia: Mihama-Kiho Project Part 21," J. Alzheimer's Dis., vol. 57, no. 1, pp. 85-96, 2017. https://doi.org/10.3233/JAD-161217

[23] Y. M. Lee, C. Jang, I. H. Bak, and J. S. Yoon, "Effects of Computer-assisted Cognitive Rehabilitation Training on the Cognition and Static Balance of the Elderly," J. Phys. Ther. Sci., vol. 25, no. 11, pp. 1475-1477, 2013. https://doi.org/10.1589/jpts. 25.1475

[24] P.-A. Kenigsberg et al., "Dementia beyond 2025: Knowledge and uncertainties," Dementia, vol. 15, no. 1, pp. 6-21, 2016. https://doi.org/10.1177/1471301215574785

[25] W. K. Leong, H. Lee, B. J. Westphal, N.-M. Cheung, and C. G. Teo, "Experience of designing and deploying a tablet game for people with dementia," pp. 31-40, 2017.

[26] H. Van Rijn, J. Van Hoof, and P. J. Stappers, "Designing leisure products for people with dementia: Developing ‘the chitchatters' game," Am. J. Alzheimers. Dis. Other Demen., vol. 25, no. 1, pp. 74-89, 2010. https://doi.org/10.1177/1533317509333039

[27] R. Gil, A. Em, P. Ingrand, M. Gil, N. Jp, and C. Ornon, "Self-consciousness and Alzheimer ', s disease," pp. 296-300, 2001. https://doi.org/10.1034/j.16000404.2001.00280.x

[28] K. M. Volkers and E. J. A. Scherder, "Impoverished environment, cognition, aging and dementia," Rev. Neurosci., vol. 22, no. 3, pp. 259-266, 2011. https://doi.org/10.1515/rns. $\underline{2011.026}$

[29] A. Iizuka et al., "Pilot Randomized Controlled Trial of the GO Game Intervention on Cognitive Function," Am. J. Alzheimers. Dis. Other Demen., vol. 33, no. 3, pp. 192-198, 2018. https://doi.org/10.1177/1533317517753362

[30] V. Faucounau, Y. H. Wu, M. Boulay, J. De Rotrou, and A. S. Rigaud, "Cognitive intervention programmes on patients affected by mild cognitive impairment: A promising intervention tool for MCI?," J. Nutr. Heal. Aging, vol. 14, no. 1, pp. 31-35, 2010. https://doi.org/10.1007/s12603-010-0006-0

[31] S.-W. Hsieh, S.-F. Hsiao, L.-J. Liaw, L.-C. Huang, and Y.-H. Yang, "Effects of multiple training modalities in the elderly with subjective memory complaints," Medicine (Baltimore)., vol. 98, no. 29, p. e16506, 2019. https://doi.org/10.1097/MD. 0000000000016506

[32] B. Bouchard, F. Imbeault, A. Bouzouane, and B.-A. J. Menelas, "Developing serious games specifically adapted to people suffering from Alzheimer BT - 3rd International Conference on Serious Games Development and Applications, SGDA 2012, September 26, 2012 - September 29, 2012,” vol. 7528 LNCS, pp. 243-254, 2012. https://doi.org/10.1007/978-3-642-33687-4_21

[33] Costa, N. M. Soares, W. A. Reis, and F. M. Bublitz, "A systematic review on the usage of games for healthcare," 5th IEEE Int. Conf. Consum. Electron. - Berlin, ICCE-Berlin 2015, pp. 480-484, 2016. https://doi.org/10.1109/ICCE-Berlin.2015.7391316

[34] S. Benveniste, P. Jouvelot, and R. Péquignot, "The MINWii project: Renarcissization of patients suffering from Alzheimer's disease through video game-based music therapy," Entertain. Comput., pp. 79-90, 2010. https://doi.org/10.1007/978-3-642-15399-0 8

[35] C. N. Xenakidis, A. M. Hadjiantonis, and G. M. Milis, "A mobile assistive application for people with cognitive decline," Proc. - 2014 Int. Conf. Interact. Technol. Games, iTAG 2014, pp. 28-35, 2014. https://doi.org/10.1109/iTAG.2014.18 
[36] A. Pyae, M. Luimula, and J. Smed, "Investigating the usability of interactive physical activity games for elderly: A pilot study," 6th IEEE Conf. Cogn. Infocommunications, CogInfoCom 2015 - Proc., pp. 185-193, 2016. https://doi.org/10.1109/CogInfo Com.2015.7390588

[37] E. E. Lithoxoidou et al., "A Gamification Engine Architecture for Enhancing Behavioral Change Support Systems," no. June, pp. 482-489, 2018. https://doi.org/10. $\underline{1145 / 3197768.3201561}$

[38] C. Stern and Z. Munn, "Cognitive leisure activities and their role in preventing dementia," Int. J. Evid. Based. Healthc., vol. 8, no. 1, pp. 2-17, 2010. https://doi.org/10.1111/j.17441609.2010.00150.X

[39] L. A. Yates, S. Ziser, A. Spector, and M. Orrell, "Cognitive leisure activities and future risk of cognitive impairment and dementia: Systematic review and meta-analysis," Int. Psychogeriatrics, vol. 28, no. 11, pp. 1791-1806, 2016. https://doi.org/10.1017/S1041610 216001137

[40] J. Verghese et al., "Leisure Activities and the Risk of Dementia in the Elderly Joe," Int. J. Clin. Exp. Med., 2003.

[41] M. K. Holden, "Virtual Environments for Motor Rehabilitation: Review," CyberPsychology Behav., vol. 8, no. 3, pp. 187-211, 2005. https://doi.org/10.1089/cpb. 2005.8.187

[42] R. Smith, “The long history of gaming in military training," Simul. Gaming, vol. 41, no. 1, pp. 6-19, 2010. https://doi.org/10.1177/1046878109334330

[43] T. M. Connolly, E. A. Boyle, E. MacArthur, T. Hainey, and J. M. Boyle, "A systematic literature review of empirical evidence on computer games and serious games," Comput. Educ., vol. 59, no. 2, pp. 661-686, 2012. https://doi.org/10.1016/j.compedu.2012.03.004

[44] D. Michael, "Serious Games - Games That Educate Train And Inform.pdf." 2005.

[45] S. Hagler, H. B. Jimison, and M. Pavel, "Assessing executive function using a computer game: Computational modeling of cognitive processes," IEEE J. Biomed. Heal. Informatics, vol. 18, no. 4, pp. 1442-1452, 2014. https://doi.org/10.1109/JBHI.2014. 2299793

[46] P. Wegrzyn, "14 Serious games in medicine," 2015.

[47] S. Valladares-Rodríguez, R. Pérez-Rodríguez, L. Anido-Rifón, and M. Fernández-Iglesias, "Trends on the application of serious games to neuropsychological evaluation: A scoping review," J. Biomed. Inform., vol. 64, pp. 296-319, 2016. https://doi.org/10.1016/ j.jbi.2016.10.019

[48] J. Li, "Examining the impact of game interventions on depression among older adults," pp. 291-294, 2014. https://doi.org/10.1145/2658537.2659009

[49] M. H. Berman and J. A. Frederick, "EFFICACY OF NEUROFEEDBACK FOR EXECUTIVE AND MEMORY FUNCTION IN DEMENTIA,” no. P4-265, 2009. https://doi.org/10.1016/j.jalz.2009.07.046

[50] D. J. Vernon, "Can neurofeedback training enhance performance? An evaluation of the evidence with implications for future research," Appl. Psychophysiol. Biofeedback, vol. 30, no. 4, pp. 347-364, 2005. https://doi.org/10.1007/s10484-005-8421-4

[51] P. C. Sierra-Correa and J. R. C. Kintz, "Ecosystem-based adaptation for improving coastal planning for sea-level rise: A systematic review for mangrove coasts," Mar. Policy, vol. 51, pp. 385-393, 2015. https://doi.org/10.1016/j.marpol.2014.09.013

[52] E. de la Guia, M. D. Lozano, and V. M. R. Penichet, "Cognitive Rehabilitation Based on Collaborative and Tangible Computer Games," 2013. https://doi.org/10.4108/icst. pervasivehealth.2013.252375

[53] A. Sisarica, L. Panesse, D. Morosini, K. Pudney, M. Rose, and N. Maiden, "Creativity support in a serious game for dementia care," p. 349, 2013. https://doi.org/10. $\underline{1145 / 2466627.2466668}$ 
[54] T. Tong and M. Chignell, "Developing a serious game for cognitive assessment: Choosing settings and measuring performance," 2nd Int. Symp. Chinese CHI, Chinese CHI 2014, pp. 70-79, 2014. https://doi.org/10.1145/2592235.2592246

[55] D. Kitakoshi, R. Hanada, K. Iwata, and M. Suzuki, "Cognitive training system for dementia prevention using memory game based on the concept of human-agent interaction," J. Adv. Comput. Intell. Intell. Informatics, vol. 19, no. 6, pp. 727-737, 2015. https://doi.org/10.20965/jaciii.2015.p0727

[56] B. J. Westphal, H. Lee, N.-M. Cheung, C. G. Teo, and W. K. Leong, "Experience of designing and deploying a tablet game for people with dementia," pp. 31-40, 2017. https://doi.org/10.1145/3152771.3152775

[57] R. Orji, R. L. Mandryk, and J. Vassileva, "Improving the Efficacy of Games for Change Using Personalization Models," ACM Trans. Comput. Interact., vol. 24, no. 5, pp. 1-22, 2017. https://doi.org/10.1145/3119929

[58] V. Vallejo et al., "Evaluation of a new serious game based multitasking assessment tool for cognition and activities of daily living: Comparison with a real cooking task," Comput. Human Behav., vol. 70, pp. 500-506, 2017. https://doi.org/10.1016/j.chb.2017.01.021

[59] V. Vallejo et al., "Evaluation of a novel Serious Game based assessment tool for patients with Alzheimer's disease," PLoS One, vol. 12, no. 5, pp. 1-14, 2017. https://doi.org/10.13 71/journal.pone.0175999

[60] M. Panagl et al., "Playful Multimodal Training for Persons with Dementia with Executive Function based Decision Support," pp. 237-240, 2018.

[61] M. Altmeyer, P. Lessel, and A. Krüger, "Investigating Gamification for Seniors Aged 75+," pp. 453-458, 2018. https://doi.org/10.1145/3196709.3196799

\section{Authors}

Laura Lim Sie-Yi is a master student in Information technology at Universiti Utara Malaysia. She is interested on Mobile game development and user interface research. Email: sieyiumm146@gmail.com

Noraziah ChePa joined UUM as a lecturer since May 2000. Having experiences in teaching more than twenty IT-related subjects for both undergraduate \& postgraduate levels and M.Sc supervisions. Having a deep interest with neuro modelling in health-related issues, she is currently working on doctoral thesis on gamebased modelling. Awarded with a BSc in Computer Science and M.Sc in Computer Science from University Science Malaysia in 1999 \& 2000 respectively. Her research activities include neuro modelling, game-based modelling, and agent simulation. Email: aziah@uum.edu.my

Article submitted 2020-01-05. Resubmitted 2020-02-14. Final acceptance 2020-02-17. Final version published as submitted by the authors. 